\title{
Lacunary statistical convergence of double sequences of sets
}

\author{
Fatih Nuray $^{1}$ - Uğur Ulusu' ${ }^{1}$ - Erdinç Dündar ${ }^{1}$
}

Published online: 1 May 2015

(C) Springer-Verlag Berlin Heidelberg 2015

\begin{abstract}
In this paper, we study the concepts of Wijsman statistical convergence, Wijsman lacunary statistical convergence, Wijsman lacunary convergence and Wijsman strongly lacunary convergence double sequences of sets and investigate the relationship among them.
\end{abstract}

Keywords Statistical convergence - Lacunary sequence . Double sequence of sets · Wijsman convergence

\section{Introduction}

Hill (1940) was the first who applied methods of functional analysis to double sequences. Also, Kull (1958) applied methods of functional analysis of matrix maps of double sequences. A lot of useful developments of double sequences in summability methods can be found in Altay and Başar (2005), Limayea and Zeltser (2009), Savaş (2010), Zeltser et al. (2009).

The concept of convergence of a sequence of real numbers has been extended to statistical convergence independently by Fast (1951) and Schoenberg (1959). This concept was extended to the double sequences by Mursaleen and Edely

Communicated by V. Loia.

Erdinç Dündar

erdincdundar79@gmail.com

Fatih Nuray

fnuray@aku.edu.tr

Uğur Ulusu

ulusu@aku.edu.tr

1 Department of Mathematics, Faculty of Science and Literature, Afyon Kocatepe University, Afyonkarahisar, Turkey
(2003). Çakan and Altay (2006) presented multidimensional analogues of the results presented by Fridy and Orhan (1997).

The concept of convergence of sequences of numbers has been extended by several authors to convergence of sequences of sets (see, Baronti and Papini 1986; Beer 1985, 1994; Nuray and Rhoades 2012; Ulusu and Nuray 2013; Wijsman 1964, 1966). Nuray and Rhoades (2012) extended the notion of convergence of set sequences to statistical convergence, and gave some basic theorems. Ulusu and Nuray (2012) defined the Wijsman lacunary statistical convergence of sequence of sets, and considered its relation with Wijsman statistical convergence, which was defined by Nuray and Rhoades. Ulusu and Nuray (2013) introduced the concept of Wijsman strongly lacunary summability for sequences of sets and discussed its relation with Wijsman strongly Cesàro summability. Nuray et al. (2015) studied the concepts of Wijsman Cesàro summability and Wijsman lacunary convergence of double sequences of sets and investigated the relationship between them. Talo and Sever (2015) examined the relationship between Kuratowski statistical convergence and Hausdorff statistical convergence.

In this paper, we study the concepts of Wijsman statistical convergence, Wijsman lacunary statistical convergence, Wijsman lacunary convergence and Wijsman strongly lacunary convergence double sequences of sets and investigate the relationship among them.

\section{Definitions and notations}

Now, we recall the basic definitions and concepts (see Altay and Başar 2005; Aubin and Frankowska 1990; Baronti and Papini 1986; Beer 1985, 1994; Nuray et al. 2015; Nuray and Rhoades 2012; Pringsheim 1900; Savaş 2010, 2012a, b; 
Sever et al. 2015; Talo and Sever 2015; Ulusu and Nuray 2013; Wijsman 1964, 1966).

For any point $x \in X$ and any non-empty subset $A$ of $X$, we define the distance from $x$ to $A$ by

$d(x, A)=\inf _{a \in A} \rho(x, a)$.

Throughout the paper, we let $(X, \rho)$ be a metric space and $A, A_{k}$ be any non-empty closed subsets of $X$.

We say that the sequence $\left\{A_{k}\right\}$ is Wijsman convergent to $A$, if

$\lim _{k \rightarrow \infty} d\left(x, A_{k}\right)=d(x, A)$

for each $x \in X$. In this case we write $W-\lim A_{k}=A$.

We say that the sequence $\left\{A_{k}\right\}$ is Wijsman statistical convergent to $A$, if for $\varepsilon>0$ and for each $x \in X$,

$\lim _{n \rightarrow \infty} \frac{1}{n}\left|\left\{k \leq n:\left|d\left(x, A_{k}\right)-d(x, A)\right| \geq \varepsilon\right\}\right|=0$.

In this case we write $s t-\lim _{W} A_{k}=A$.

By a lacunary sequence we mean an increasing integer sequence $\theta=\left\{k_{r}\right\}$ such that $k_{0}=0$ and $h_{r}=k_{r}-k_{r-1} \rightarrow$ $\infty$ as $r \rightarrow \infty$. Throughout this paper the intervals determined by $\theta$ will be denoted by $I_{r}=\left(k_{r-1}, k_{r}\right]$, and ratio $\frac{k_{r}}{k_{r-1}}$ will be abbreviated by $q_{r}$.

Let $\theta=\left\{k_{r}\right\}$ be a lacunary sequence. We say that the sequence $\left\{A_{k}\right\}$ is Wijsman lacunary summable to $A$, if for each $x \in X$,

$\lim _{r \rightarrow \infty} \frac{1}{h_{r}} \sum_{k \in I_{r}} d\left(x, A_{k}\right)=d(x, A)$.

In this case we write $A_{k} \rightarrow A\left(W N_{\theta}\right)$.

Let $\theta=\left\{k_{r}\right\}$ be a lacunary sequence. We say that the sequence $\left\{A_{k}\right\}$ is Wijsman strongly lacunary summable to $A$, if for each $x \in X$,

$\lim _{r \rightarrow \infty} \frac{1}{h_{r}} \sum_{k \in I_{r}}\left|d\left(x, A_{k}\right)-d(x, A)\right|=0$.

In this case we write $A_{k} \rightarrow A\left(\left[W N_{\theta}\right]\right)$.

We say that the sequence $\left\{A_{k}\right\}$ is Wijsman lacunary statistically convergent to $A$, if for $\varepsilon>0$ and for each $x \in X$,

$\lim _{r} \frac{1}{h_{r}}\left|k \in I_{r}:\right| d\left(x, A_{k}\right)-d(x, A)|\geq \varepsilon|=0$.

A double sequence $x=\left(x_{k j}\right)_{k, j \in \mathbb{N}}$ of real numbers is said to be convergent to $L \in \mathbb{R}$ in Pringsheim's sense if for any $\varepsilon>0$, there exists $N_{\varepsilon} \in \mathbb{N}$ such that $\left|x_{k j}-L\right|<\varepsilon$, whenever $k, j>N_{\varepsilon}$. In this case we write

$P-\lim _{k, j \rightarrow \infty} x_{k j}=L$ or $\lim _{k, j \rightarrow \infty} x_{k j}=L$.

A double sequence $x=\left(x_{k j}\right)$ of real numbers is said to be bounded if there exists a positive real number $M$ such that $\left|x_{k j}\right|<M$, for all $k, j \in \mathbb{N}$. That is

$\|x\|_{\infty}=\sup _{k, j}\left|x_{k j}\right|<\infty$.

Throughout the paper, $A, A_{k j}$ be any non-empty closed subsets of $X$.

The double sequence $\left\{A_{k j}\right\}$ is Wijsman convergent to $A$, if for each $x \in X$

$$
\begin{gathered}
P-\lim _{k, j \rightarrow \infty} d\left(x, A_{k j}\right)=d(x, A) \text { or } \\
\lim _{k, j \rightarrow \infty} d\left(x, A_{k j}\right)=d(x, A) .
\end{gathered}
$$

In this case we write $W_{2}-\lim A_{k j}=A$.

We say that the double sequence $\left\{A_{k j}\right\}$ is Wijsman statistically convergent to $A$, if for each $\varepsilon>0$ and for each $x \in X$,

$\lim _{m, n \rightarrow \infty} \frac{1}{m n}\left|\left\{k \leq m, j \leq n:\left|d\left(x, A_{k j}\right)-d(x, A)\right| \geq \varepsilon\right\}\right|=0$,

that is,

$\left|d\left(x, A_{k j}\right)-d(x, A)\right|<\varepsilon, \quad$ a.a. $(\mathrm{k}, \mathrm{j})$.

In this case we write $s t_{2}-\lim _{W} A_{k}=A$.

The set of Wijsman statistically convergent double sequences will be denoted by

$W_{2} S:=\left\{\left\{A_{k j}\right\}: s t_{2}-\lim _{W} A_{k j}=A\right\}$.

The double sequence $\theta=\left\{\left(k_{r}, j_{s}\right)\right\}$ is called double lacunary sequence if there exist two increasing sequence of integers such that

$k_{0}=0, \quad h_{r}=k_{r}-k_{r-1} \rightarrow \infty \quad$ as $\quad r \rightarrow \infty$

and

$j_{0}=0, \quad \bar{h}_{u}=j_{u}-j_{u-1} \rightarrow \infty \quad$ as $\quad u \rightarrow \infty$.

We use following notations in the sequel:

$k_{r u}=k_{r} j_{u}, h_{r u}=h_{r} \bar{h}_{u}, \quad I_{r u}=\left\{(k, j): k_{r-1}<k \leq k_{r}\right.$ and $\left.j_{u-1}<j \leq j_{u}\right\}$, 
$q_{r}=\frac{k_{r}}{k_{r-1}}$ and $q_{u}=\frac{j_{u}}{j_{u-1}}$.

Let $\theta=\left\{\left(k_{r}, j_{s}\right)\right\}$ be a double lacunary sequence. The double sequence $\left\{A_{k j}\right\}$ is Wijsman lacunary convergent to $A$, if for each $x \in X$,

$\lim _{r, u \rightarrow \infty} \frac{1}{h_{r} \bar{h}_{u}} \sum_{k=k_{r-1}+1}^{k_{r}} \sum_{j=j_{u-1}+1}^{j_{u}} d\left(x, A_{k j}\right)=d(x, A)$.

In this case we write $A_{k j} \stackrel{\left(W_{2} N_{\theta}\right)}{\longrightarrow} A$ Let $\theta=\left\{\left(k_{r}, j_{s}\right)\right\}$ be a double lacunary sequence. The double sequence $\left\{A_{k j}\right\}$ is Wijsman strongly lacunary convergent to $A$, if for each $x \in X$,

$\lim _{r, u \rightarrow \infty} \frac{1}{h_{r} \bar{h}_{u}} \sum_{k=k_{r-1}+1}^{k_{r}} \sum_{j=j_{u-1}+1}^{j_{u}}\left|d\left(x, A_{k j}\right)-d(x, A)\right|=0$.

In this case we write $A_{k j} \stackrel{\left[\mathrm{W}_{2} \mathrm{~N}_{\theta}\right]}{\longrightarrow} A$.

Let $\theta=\left\{\left(k_{r}, j_{s}\right)\right\}$ be a double lacunary sequence. The double sequence $\left\{A_{k j}\right\}$ is Wijsman strongly $p$-lacunary convergent to $A$, if for each $p$ positive real number and for each $x \in X$,

$\lim _{r, u \rightarrow \infty} \frac{1}{h_{r} \bar{h}_{u}} \sum_{k=k_{r-1}+1}^{k_{r}} \sum_{j=j_{u-1}+1}^{j_{u}}\left|d\left(x, A_{k j}\right)-d(x, A)\right|^{p}=0$.

In this case we write $A_{k j} \stackrel{\left[W_{2}^{p} N_{\theta}\right]}{\longrightarrow} A$.

\section{Main results}

In this section, we will define the notions of Wijsman lacunary convergence, Wijsman strongly lacunary convergence and Wijsman lacunary statistical convergence of double sequences of sets and investigate the relationship among them. Also we will give the relationship between Wijsman statistical convergence and Wijsman lacunary statistical convergence of double sequences of sets.

Definition 3.1 We say that the double sequence $\left\{A_{k j}\right\}$ is Wijsman lacunary statistically convergent to $A$, if for each $\varepsilon>0$ and for each $x \in X$,

$\lim _{r, u \rightarrow \infty} \frac{1}{h_{r} \bar{h}_{u}}\left|\left\{(k, j) \in I_{r u}:\left|d\left(x, A_{k j}\right)-d(x, A)\right| \geq \varepsilon\right\}\right|=0$.

In this case we write $s t_{2}-\lim _{W_{\theta}} A_{k j}=A$.

The set of Wijsman lacunary statistically convergent double sequences will be denoted by

$W_{2} S_{\theta}:=\left\{\left\{A_{k j}\right\}: s t_{2}-\lim _{W_{\theta}} A_{k j}=A\right\}$.
Example 3.2 Let $X=\mathbb{R}$ and we define a double sequence $\left\{A_{k j}\right\}$ as follows:

$A_{k j}:=\left\{\begin{array}{c}\left\{(x, y) \in \mathbb{R}^{2}: 2 \leq x \leq k_{r}-k_{r-1}, 2 \leq y \leq j_{u}-j_{u-1}\right\} \\ \text { if } k, j \geq 2 \text { and } k, j \text { is square integer, } \\ \{(1,1)\} \text { otherwise. }\end{array}\right.$

This sequence is not Wijsman lacunary summable. But since

$$
\begin{gathered}
\lim _{r, u \rightarrow \infty} \frac{1}{h_{r} \bar{h}_{u}} \mid\left\{(k, j) \in I_{r u}:\left|d\left(x, A_{k j}\right)-d(x,\{(1,1)\})\right|\right. \\
\geq \varepsilon\} \mid=\lim _{r, u \rightarrow \infty} \frac{\sqrt{\left(k_{r}-k_{r-1}\right)\left(j_{u}-j_{u-1}\right)}}{h_{r} \bar{h}_{u}}=0
\end{gathered}
$$

this sequence is Wijsman lacunary statistically convergent to the set $A=\{(1,1)\}$.

Theorem 3.3 (i) If $\left\{A_{k j}\right\}$ is Wijsman strongly lacunary convergent to $A$, then $\left\{A_{k j}\right\}$ is Wijsman lacunary statistical convergent to $A$

(ii) $\left[W_{2} N_{\theta}\right]$ is a proper subset of $\left(W_{2} S_{\theta}\right)$.

Proof (i) if $\varepsilon>0$ and $A_{k j} \rightarrow A\left(\left[W_{2} N_{\theta}\right]\right)$ we can write

$$
\begin{aligned}
& \sum_{(k, j) \in I_{r u}}\left|d\left(x, A_{k j}\right)-d(x, A)\right| \\
& \geq \sum_{\substack{(k, j) \in I_{r u} \\
\left|d\left(x, A_{k j}\right)-d(x, A)\right| \geq \varepsilon}}\left|d\left(x, A_{k j}\right)-d(x, A)\right| \\
& \geq \varepsilon \cdot\left|\left\{(k, j) \in I_{r u}:\left|d\left(x, A_{k j}\right)-d(x, A)\right| \geq \varepsilon\right\}\right|
\end{aligned}
$$

which gives the result.

(ii) In order to show that the inclusion $\left[W_{2} N_{\theta}\right] \subset W_{2} S_{\theta}$ in ( $i$ ) is proper, let $\theta$ be given and we define a sequence $\left\{A_{k j}\right\}$ as follows:

$A_{k j}=\left\{\begin{array}{c}\{(k, j)\}, \quad \text { if } k_{r-1}<k \leq k_{r-1}+\left[\sqrt{h_{r}}\right], \\ j_{u-1}<j \leq j_{u-1}+\left[\sqrt{\bar{h}_{u}}\right],(r, u=1,2, \cdots) \\ \{(0,0)\}, \quad \text { otherwise. }\end{array}\right.$

Note that $\left\{A_{k j}\right\}$ is not bounded. We have, for every $\varepsilon>0$ and for each $x \in X$,

$$
\begin{aligned}
& \frac{1}{h_{r} \bar{h}_{u}}\left|\left\{(k, j) \in I_{r u}:\left|d\left(x, A_{k j}\right)-d(x,\{(0,0)\})\right| \geq \varepsilon\right\}\right| \\
& \quad=\frac{\left[\sqrt{h_{r}}\right]\left[\sqrt{\bar{h}_{u}}\right]}{h_{r} \bar{h}_{u}} \rightarrow 0 \text { as } r, u \rightarrow \infty, \\
& \text { i.e., } A_{k j} \rightarrow\{(0,0)\}\left(W_{2} S_{\theta}\right) \text {. But, }
\end{aligned}
$$




$$
\begin{aligned}
& \frac{1}{h_{r} \bar{h}_{u}} \sum_{(k, j) \in I_{r u}} \mid d\left(x, A_{k j}\right)-d(x,\{(0,0)\} \mid \\
& =\frac{1}{h_{r} \bar{h}_{u}} \frac{\left(\left[\sqrt{h_{r}}\right] \cdot\left(\left[\sqrt{h_{r}}\right]+1\right)\right)\left(\left[\sqrt{\bar{h}_{u}}\right] \cdot\left(\left[\sqrt{\bar{h}_{u}}\right]+1\right)\right)}{4} \\
& \rightarrow \frac{1}{4} \neq 0 .
\end{aligned}
$$

Hence $A_{k j} \nrightarrow\{(0,0)\}\left(\left[W_{2} N_{\theta}\right]\right)$.

Theorem 3.4 Let $L_{\infty}$ be a set of bounded double sequences of sets. If $\left\{A_{k j}\right\} \in L_{\infty}$ and $\left\{A_{k j}\right\}$ is Wijsman lacunary statistical convergent to $A$, then $\left\{A_{k j}\right\}$ is Wijsman strongly lacunary convergent to A.

Proof Suppose that $\left\{A_{k j}\right\} \in L_{\infty}$ and $A_{k j} \rightarrow A\left(W_{2} S_{\theta}\right)$, say $\left|d\left(x, A_{k j}\right)-d(x, A)\right| \leq M$ for each $x \in X$ and all $(k, j)$. Given $\varepsilon>0$, we get

$$
\begin{aligned}
& \frac{1}{h_{r} \bar{h}_{u}} \sum_{(k, j) \in I_{r u}}\left|d\left(x, A_{k j}\right)-d(x, A)\right| \\
& =\frac{1}{h_{r} \bar{h}_{u}} \sum_{\substack{(k, j) \in I_{r u} \\
\left|d\left(x, A_{k j}\right)-d(x, A)\right| \geq \varepsilon}}\left|d\left(x, A_{k j}\right)-d(x, A)\right| \\
& \quad+\frac{1}{h_{r} \bar{h}_{u}} \sum_{\substack{(k, j) \in I_{r u} \\
\left|d\left(x, A_{k j}\right)-d(x, A)\right|<\varepsilon}}\left|d\left(x, A_{k j}\right)-d(x, A)\right| \\
& \leq \frac{M}{h_{r} \bar{h}_{u}}\left|\left\{(k, j) \in I_{r u}:\left|d\left(x, A_{k j}\right)-d(x, A)\right| \geq \varepsilon\right\}\right|+\varepsilon,
\end{aligned}
$$

for each $x \in X$. Hence we have the result.

Theorem 3.5 $\left\{W_{2} S_{\theta}\right\} \cap L_{\infty}=\left\{\left[W_{2} N_{\theta}\right]\right\} \cap L_{\infty}$.

Proof This follows from consequences Theorems 3.3 and 3.4.

Theorem 3.6 For any double lacunary sequence $\theta=$ $\left\{\left(k_{r}, j_{s}\right)\right\}$, if $\liminf _{r} q_{r}>1$ and $\liminf _{u} q_{u}>1$, then $s t_{2}-\lim _{W} A_{k j}=A$ implies $s t_{2}-\lim _{W_{\theta}} A_{k j}=A$.

Proof Assume that $\liminf _{r} q_{r}>1$, and $\liminf _{u} q_{u}>1$, then there exist $\lambda, \mu>0$ such that $q_{r} \geq 1+\lambda$ and $q_{u} \geq 1+\mu$ for sufficiently large $r, u$ which implies that

$$
\frac{h_{r} \bar{h}_{u}}{k_{r u}} \geq \frac{\lambda \mu}{(1+\lambda)(1+\mu)} .
$$

If $s t_{2}-\lim _{W} A_{k j}=A$, then for every $\varepsilon>0$ and for sufficiently large $r, u$ we have

$$
\begin{aligned}
& \frac{1}{k_{r} j_{u}}\left|\left\{k \leq k_{r}, j \leq j_{u}:\left|d\left(x, A_{k j}\right)-d(x, A)\right| \geq \varepsilon\right\}\right| \\
& \geq \frac{1}{k_{r} j_{u}}\left|\left\{(k, j) \in I_{r u}:\left|d\left(x, A_{k j}\right)-d(x, A)\right| \geq \varepsilon\right\}\right| \\
& \geq \frac{\lambda \mu}{(1+\lambda)(1+\mu)} \\
& \cdot\left(\frac{1}{h_{r} \bar{h}_{u}}\left|\left\{(k, j) \in I_{r u}:\left|d\left(x, A_{k j}\right)-d(x, A)\right| \geq \varepsilon\right\}\right|\right) .
\end{aligned}
$$

for each $x \in X$. Hence, $s t_{2}-\lim _{W_{\theta}} A_{k j}=A$.

Theorem 3.7 For any double lacunary sequence $\theta=$ $\left\{\left(k_{r}, j_{s}\right)\right\}$, if $\lim \sup _{r} q_{r}<\infty$ and $\lim \sup _{u} q_{u}<\infty$, then $s t_{2}-\lim _{W_{\theta}} A_{k j}=A$ implies $s t_{2}-\lim _{W} A_{k j}=A$.

Proof If $\lim \sup _{r} q_{r}<\infty$ and $\lim \sup _{u} q_{u}<\infty$, then there is an $M, N>0$ such that $q_{r}<M$ and $q_{u}<N$, for all $r, u$. Suppose that $s t_{2}-\lim _{W_{\theta}} A_{k j}=A$ and let

$$
\begin{aligned}
U_{r u}= & U(r, u, x):=\mid\left\{(k, j) \in I_{r u}: \mid d\left(x, A_{k j}\right)\right. \\
& -d(x, A)|\geq \varepsilon| .
\end{aligned}
$$

Then, given $\varepsilon>0$, there is an $r_{0}, u_{0} \in \mathbb{N}$ such that $\frac{U_{r u}}{h_{r} \bar{h}_{u}}<\varepsilon$, for all $r>r_{0}, u>u_{0}$.

Now let

$K:=\max \left\{U_{r u}: 1 \leq r \leq r_{0}, 1 \leq u \leq u_{0}\right\}$

and let $t$ and $v$ be any integers satisfying $k_{r-1}<t \leq k_{r}$ and $j_{u-1}<v \leq j_{u}$. Then we can write

$$
\begin{aligned}
& \frac{1}{t v}\left|\left\{k \leq t, j \leq v:\left|d\left(x, A_{k j}\right)-d(x, A)\right| \geq \varepsilon\right\}\right| \\
& \leq \frac{1}{k_{r-1} j_{u-1}}\left|\left\{k \leq k_{r}, j \leq j_{u}:\left|d\left(x, A_{k j}\right)-d(x, A)\right| \geq \varepsilon\right\}\right| \\
& =\frac{1}{k_{r-1} j_{u-1}}\left\{U_{11}+U_{12}+U_{21}+U_{22}+\cdots+U_{r_{0} u_{0}}+\cdots+U_{r u}\right\} \\
& \leq \frac{K}{k_{r-1} j_{u-1}} \cdot r_{0} u_{0}+\frac{1}{k_{r-1} j_{u-1}} \\
& \times\left\{h_{r_{0}} \bar{h}_{u_{0}+1} \frac{U_{r_{0}, u_{0}+1}}{h_{r_{0}} \bar{h}_{u_{0}+1}}+h_{r_{0}+1} \bar{h}_{u_{0}} \frac{U_{r_{0}+1, u_{0}}}{h_{r_{0}+1} \bar{h}_{u_{0}}}+\cdots+h_{r} \bar{h}_{u} \frac{U_{r u}}{h_{r} \bar{h}_{u}}\right\} \\
& \leq \frac{r_{0} u_{0} \cdot K}{k_{r-1} j_{u-1}}+\frac{1}{k_{r-1} j_{u-1}}\left(\sup _{\substack{r>r_{0} \\
u>u_{0}}} \frac{U_{r u}}{h_{r} \bar{h}_{u}}\right) \\
& \times\left\{h_{r_{0}} \bar{h}_{u_{0}+1}+h_{r_{0}+1} \bar{h}_{u_{0}}+\cdots+h_{r} \bar{h}_{u}\right\} \\
& \leq \frac{r_{0} u_{0} \cdot K}{k_{r-1} j_{u-1}}+\varepsilon \cdot \frac{\left(k_{r}-k_{r_{0}}\right)\left(j_{u}-j_{u_{0}}\right)}{k_{r-1} j_{u-1}} \\
& \leq \frac{r_{0} u_{0} \cdot K}{k_{r-1} j_{u-1}}+\varepsilon \cdot q_{r} \cdot q_{u} \leq \frac{r_{0} u_{0} \cdot K}{k_{r-1} j_{u-1}}+\varepsilon \cdot M \cdot N
\end{aligned}
$$


and the sufficiently follows immediately.

Theorem 3.8 For any double lacunary sequence $\theta=$ $\left\{\left(k_{r}, j_{S}\right)\right\}$, if $1<\liminf _{r} q_{r} \leq \limsup _{r} q_{r}<\infty$ and $1<\liminf _{u} q_{u} \leq \limsup _{u} q_{u}<\infty$ then $W_{2} S=W_{2} S_{\theta}$.

Proof This follows from Theorems 3.6 and 3.7.

Theorem 3.9 If $\left\{A_{k j}\right\} \in W_{2} S \cap W_{2} S_{\theta}$, then $s t_{2}-\lim _{W_{\theta}} A_{k j}$ $=s t_{2}-\lim _{W} A_{k j}$.

Proof Suppose that $s t-\lim _{W} A_{k j}=A$ and $s t_{2}-\lim _{W_{\theta}} A_{k j}$ $=B$ and $A \neq B$. For

$\frac{1}{2}|d(x, A)-d(x, B)|>\varepsilon$

and each $x \in X$ we get

$\lim _{m, n \rightarrow \infty} \frac{1}{m n}\left|\left\{k \leq m, j \leq n:\left|d\left(x, A_{k j}\right)-d(x, B)\right| \geq \varepsilon\right\}\right|=1$.

Consider the $k_{t} j_{v}$ th term of the statistical limit expression

$$
\begin{aligned}
& \frac{1}{m n}\left|\left\{k \leq n, j \leq n:\left|d\left(x, A_{k j}\right)-d(x, B)\right| \geq \varepsilon\right\}\right|: \\
& \frac{1}{k_{t} j_{v}}\left|\left\{k \leq k_{t}, j \leq j_{v}:\left|d\left(x, A_{k j}\right)-d(x, B)\right| \geq \varepsilon\right\}\right| \\
& =\frac{1}{k_{t} j_{v}}\left|\left\{(k, j) \in \bigcup_{r, u=1,1}^{t, v} I_{r u}:\left|d\left(x, A_{k j}\right)-d(x, B)\right| \geq \varepsilon\right\}\right| \\
& =\frac{1}{k_{t} j_{v}} \cdot \sum_{r, u=1,1}^{t, v}\left|\left\{(k, j) \in I_{r u}:\left|d\left(x, A_{k j}\right)-d(x, B)\right| \geq \varepsilon\right\}\right| \\
& =\frac{1}{\sum_{r, u=1,1}^{t, v} h_{r} \bar{h}_{u}} \cdot \sum_{r, u=1,1}^{t, v} \mid\left\{(k, j) \in I_{r u}: \mid d\left(x, A_{k j}\right)\right. \\
& \quad-d(x, B) \mid \geq \varepsilon\} \mid, \sum_{t, v}^{t, v} h_{r} \bar{h}_{u} s_{r u}, \\
& =\frac{1}{\sum_{r, u=1,1}^{t, v} h_{r} \bar{h}_{u}} \cdot \sum_{r, u=1,1}
\end{aligned}
$$

where $s_{r u}=\frac{1}{h_{r} \bar{h}_{u}} \mid\left\{(k, j) \in I_{r u}:\left|d\left(x, A_{k j}\right)-d(x, B)\right| \geq\right.$ $\varepsilon\} \mid \rightarrow 0$ because $A_{k j} \rightarrow B\left(W_{2} S_{\theta}\right)$. Since $\theta$ is double lacunary sequence,

$\frac{1}{\sum_{r, u=1,1}^{t, v} h_{r} \bar{h}_{u}} \cdot \sum_{r, u=1,1}^{t, v} h_{r} \bar{h}_{u} s_{r u}$

is a regular weighted mean transform of $s_{r u}$, (see Fridy and Orhan 1993; Ulusu and Nuray 2012), and therefore it too tends to zero as $t, v \rightarrow \infty$. Also, since this is a subsequence of

$$
\left\{\frac{1}{m n} \mid\left\{k \leq m, j \leq n:\left|d\left(x, A_{k j}\right)-d(x, B)\right| \geq \varepsilon\right\}\right\}_{m, n=1,1}^{\infty, \infty},
$$

we infer that

$$
\begin{aligned}
& \lim _{m, n \rightarrow \infty} \frac{1}{m n} \mid\left\{k \leq m, j \leq n: \mid d\left(x, A_{k j}\right)\right. \\
& \quad-d(x, B) \mid \geq \varepsilon\} \mid \neq 1,
\end{aligned}
$$

and this contradiction shows that we cannot have $A \neq B$.

\section{References}

Altay B, Başar F (2005) Some new spaces of double sequences. J Math Anal Appl 309(1):70-90

Aubin J-P, Frankowska H (1990) Set-valued analysis. Birkhauser, Boston

Baronti M, Papini P (1986) Convergence of sequences of sets. In: Proceedings of methods of functional analysis in approximation theory, ISNM 76, Birkhauser, Basel, pp 133-155

Beer G (1985) On convergence of closed sets in a metric space and distance functions. Bull Aust Math Soc 31:421-432

Beer G (1994) Wijsman convergence: a survey. Set-Valued Var Anal 2:77-94

Connor JS (1988) The statistical and strong p-Cesaro convergence of sequences. Analysis 8:46-63

Çakan C, Altay B (2006) Statistically boundedness and statistical core of double sequences. J Math Anal Appl 317:690-697

Fast H (1951) Sur la convergence statistique. Colloq Math 2:241-244

Freedman AR, Sember JJ, Raphael M (1978) Some Cesàro type summability spaces. Proc Lond Math Soc 37:508-520

Fridy JA, Orhan C (1997) Statistical limit superior and inferior. Proc Am Math Soc 125:3625-3631

Fridy JA, Orhan C (1993) Lacunary statistical convergence. Pac J Math 160(1):43-51

Hill JD (1940) On perfect summability of double sequences. Bull Am Math Soc 46:327-331

Kull IG (1958) Multiplication of summable double series, Uch. zap. Tartusskogo un-ta 62 (1958), 3 Ü59 (in Russian)

Limayea BV, Zeltser M (2009) On the Pringsheim convergence of double series. Proc Est Acad Sci 58:108-121

Mursaleen OHH (2003) Edely, statistical convergence of double sequences. J Math Anal Appl 288:223-231

Nuray F, Rhoades BE (2012) Statistical convergence of sequences of sets. Fasc Math 49:87-99

Nuray F, Ulusu U, Dündar E (2015) On cesàro summability of double sequences of sets. Gen Math Notes (Accepted in press)

Pringsheim A (1900) Zur theorie der zweifach unendlichen Zahlenfolgen. Math Ann 53:289-321

Rockafellar RT, Wets RJ-B (2009) Variational Analysis, Grundlehren der Mathematischen Wissenschaften 317, Springer, New York

Savaş E (2010) On some double lacunary sequence spaces of fuzzy numbers. Math Comput Appl 15(3):439-448

Savaş E (2012) A note on double lacunary statistical sigma-convergence of fuzzy numbers. Soft Comput 16(4):591-595

Savaş E (2012) Some double lacunary I-convergent sequence spaces of fuzzy numbers defined by Orlicz function. J Intell Fuzzy Syst 23(5):249-257

Schoenberg IJ (1959) The integrability of certain functions and related summability methods. Am Math Mon 66:361-375

Talo Ö, Sever Y (2015) On statistically convergence of double sequence of closed sets, (under communication)

Sever Y, Talo Ö, Altay B (2015) On convergence of double sequence of closed sets, (under communication)

Ulusu U, Nuray F (2012) Lacunary statistical convergence of sequence of sets. Prog Appl Math 4(2):99-109 
Ulusu U, Nuray F (2013) On strongly lacunary summability of sequences of sets. J Appl Math Bioinform 3(3):75-88

Wijsman RA (1964) Convergence of sequences of convex sets, cones and functions. Bull Am Math Soc 70:186-188

Wijsman RA (1966) Convergence of sequences of convex sets, cones and functions II. Trans Am Math Soc 123(1):32-45
Zeltser M, Mursaleen M, Mohiuddine SA (2009) On almost conservative matrix methods for double sequence spaces. Publ Math Debrecen 75:1-13 